\title{
Morbidity and Mortality of Patients Submitted to Radical Prostatectomy in a Teaching Hospital
}

\author{
Thiago da Silveira Antoniassi ${ }^{1}$, Maria Fernanda W. Facio², \\ Jeronimo Jose $\mathrm{Neto}^{3}$, Lais Ferraz de Arruda4, Daniel Almeida de \\ Oliveira ${ }^{5}$, Marcio Gatti, Pedro Francisco Arruda ${ }^{6}$, Felipe Azenha \\ Lamônica7, Germano José Ferraz de Arruda ${ }^{8}$, Luis César Fava \\ Spessoto9, Fernando Nestor Fácio Junior ${ }^{10}$
}

1,2,3,4,5,6,7,8,9,10 Urology Department of the Medicine School in São José do Rio Preto (FAMERP)

\begin{abstract}
Screening for prostate cancer has contributed to an increase in the diagnosis of tumors, probably of moderately differentiated tumors and consequent reduction in the mortality rate. Radical prostatectomy surgery (RPT), along with radiotherapy, brachytherapy, and in some selected cases, active surveillance, is considered the gold standard in the treatment of localized adenocarcinoma of the prostate. The aim of this study was to evaluate the complications of patients undergoing RPT in Hospital de Base São José do Rio Preto. A retrospective study was carried out in 78 patients through a review of patient records between January 2005 and December 2010. Descriptive statistical analysis was used. Of the 78 patients included in this study, 71 had complications related to the surgical procedure. Common morbidities included erectile dysfunction $(55.1 \%)$ and urinary incontinence (44.8\%). Complications mainly occurred in patients older than 70 years (49\%). The mortality rate due to postoperative complications was $1.2 \%$. Post-operative complication rates in this study are consistent with previous studies although the mortality rate was slightly higher may reflect the experience of the surgeons who performed the procedure.
\end{abstract}

Keywords: Prostate cancer; Radical prostatectomy; Morbidity; Mortality

\section{Introduction}

With increases in life expectancy, diseases such as prostate cancer, which are more common in the aged but can potentially be detected and treated early, have grown in importance.

Screening for prostate cancer has contributed to early diagnosis with tumors being found in younger patients probably including a higher incidence of moderately differentiated disease (Roach et al., 2007). There are indications that mortality from prostate cancer is decreasing thereby showing the importance of screening (Ries et al., 2002).

All therapeutic options [radiotherapy, brachytherapy and radical prostatectomy surgery (RPT)] have a low risk of relapse or metastasis in patients with very low to moderate risk. In some carefully selected cases, in which patients have low or very low risk, active surveillance may be a treatment option. The decision on the therapeutic approach depends on the patient's choice after detailed clarification of the advantages and disadvantages of each treatment option (Jarosek et al., 2015). Walsh \& Donker (1982) described the technique of RPT with preservation of the neurovascular bundle. However, at that time this procedure was little used because of technical difficulties that increased the mortality rate (Walsh \& Donker, 1982; Souto et al., 2004).

Complications rates vary greatly after RPT depending on the experience of the surgeon carrying out the procedure. For example, rates of urethral stenosis can vary from $0.48-32 \%$ (Hisasue et al., 2004), between $44 \%$ and $75 \%$ of patients develop erectile dysfunction (Sanda et al., 2008) and from $2 \%$ to $60 \%$ evolve with urinary incontinence (Glazener et al., 2011).

The aim of this study was to evaluate the morbidity and mortality rates in patients submitted to RPT

This article is published under the terms of the Creative Commons Attribution License 4.0

Author(s) retain the copyright of this article. Publication rights with Alkhaer Publications.

Published at: http://www.ijsciences.com/pub/issue/2016-07/

DOI: 10.18483/ijSci.1034; Online ISSN: 2305-3925; Print ISSN: 2410-4477 
treated by residents under training in a teaching hospital.

\section{Methods}

This retrospective study included patients with localized prostate tumors who were submitted to RPT between January 2005 and December 2010 in Hospital de Base of the Medicine School in São José do Rio Preto (FAMERP).

This study was approved by the Research Ethics Committee of FAMERP.

In the period, 614 patients underwent RPT to treat prostate cancer. Patients who had prostate specific antigen (PSA) levels greater than $20 \mathrm{ng} / \mathrm{mL}$ prior to surgery or a Gleason index greater than 7 on biopsy were excluded from the study because this kind of patient are at high risk, generally without any possible cure and sometimes with metastasis. Thus, the postoperative medical records of 78 (12.70\%) cases were evaluated in respect to morbidity and mortality over a period of twelve months. Descriptive statistical analysis was used.

\section{Results}

Of the 78 patients who were treated surgically for prostate cancer and included in this study, 71 had some type of postoperative complication. Only one patient died as a direct cause of postoperative complications, representing a mortality rate of $1.2 \%$.

The main complications found in this study were erectile dysfunction $(55.1 \%)$ and urinary incontinence $(44.8 \%)$. Other important complications were also reported such as urinary infection (30.7\%), urethral stenosis (15\%) and postoperative wound infection (11.5\%) (Table 1).

Table 1 - Postoperative complications

\begin{tabular}{lll}
\hline Complication & $\mathrm{n}$ & $\%$ \\
\hline Erectile dysfunction & 43 & 55.1 \\
Urinary incontinence & 35 & 44.8 \\
Urinary tract infection & 24 & 30.7 \\
Urethral stenosis & 15 & 19.2 \\
Surgical wound infection & 9 & 11.5 \\
Fistula & 2 & 2.5 \\
Suture dehiscence & 4 & 5.1 \\
Incisional hernia & 3 & 3.8 \\
\hline
\end{tabular}

The ages of the participants of this study ranged from 49 to 75 years, with an average age of 66 years. The highest rates of absolute (67\%) and relative (49\%) complications were seen in over 70 -year-old patients (Table 2).

Table 2 - Complications stratified by age

\begin{tabular}{lllll}
\hline & Age & & & \\
\hline & $40-49$ & $50-59$ & $60-69$ & $>70$ \\
\hline Number of patients & 1 & 14 & 37 & 26 \\
Erectile dysfunction & 1 & 7 & 23 & 13 \\
Urinary incontinence & 0 & 6 & 17 & 12 \\
Urinary tract infection & 1 & 6 & 10 & 8 \\
Urethral stenosis & 0 & 5 & 7 & 2 \\
Surgical wound infection & 0 & 1 & 4 & 4 \\
Suture dehiscence & 0 & 0 & 3 & 1 \\
Fistula & & & & \\
Incisional hernia & 0 & 0 & 1 & 1 \\
\hline
\end{tabular}

\section{Discussion}

RPT is widely used in the treatment of localized prostate cancer. Advances in surgical techniques, anesthesia and postoperative care have led to a reduction in the morbidity rates (Hanchanale et al., 2010).
Furthermore, the mortality rate has been reducing over the years with most referral centers and general hospitals having rates of less than $1 \%$ (Alibhai et al., 2005; Eggener et al., 2011). The current study reports a slightly higher mortality rate than that found in the literature, which may reflect the experience of the surgeons who performed the procedure although 
comorbidities that might explain this finding were not investigated.

Several studies have reported erectile dysfunction rates ranging from 14 to $90 \%$. Bergman et al. reported a rate between 30 and $50 \%$ of erectile dysfunction five years after radical prostatectomy (12). The rate in the current study was $55 \%$, which is consistent with previous studies.

The rate of urinary incontinence in previous studies ranged from 5-20\% one year after surgery. In patients with stenosis of the proximal urethra, the rate can be as high as $46.5 \%$ (Defade et al., 2011). The rate in the current series was $35 \%$.

This study found a higher rate of complications in over 70-year-old patients (49\%). No published studies have described this relationship.

\section{Conclusion}

Postoperative complication rates found in Hospital de Base in São José do Rio Preto, Brazil are consistent with the findings in the literature, with only mortality proving to be slightly higher.

\section{References}

1) Roach M 3rd, Weinberg V, Sandler H, Thompson I. Staging for prostate cancer: time to incorporate pretreatment prostatespecific antigen and Gleason score? Cancer 2007; 109:213.

2) Ries LAG, Eisner, MP, Kosary, CL, et al. SEER Cancer Statistics Review, 1973-1999. National Cancer Institute, Bethesda, MD, 2002.
3) Jarosek SL, Virnig BA, Chu H, Elliott SP. Propensityweighted long-term risk of urinary adverse events after prostate cancer surgery, radiation, or both. Eur Urol 2015; 67:273.

4) Walsh PC, Donker PJ. Impotence following radical prostatectomy: insight into etiology and prevention. J Urol 1982;128(3):492-7.

5) Souto CAV, Rhoden EL, De Conti R, Chammas Jr. M, Laste SE, Fornari A ET AL. Urethral catheter removal 7 or 14 days after radical retropubic prostatectomy: clinical implications and complications in a randomized study. Rev Hosp Clin 2004;59(5):262-265.

6) Hisasue S, Takahashi A, Kato R, Shimizu T, Masumori N, Itoh $\mathrm{N}$, et al. Early and late complications of radical retropubic prostatectomy: Experience in a single institution. Jpn J Clin Oncol.2004;34:274-9.

7) Sanda MG, Dunn RL, Michalski J, et al. Quality of life and satisfaction with outcome among prostate-cancer survivors. N Engl J Med 2008; 358:1250.

8) Glazener C, Boachie C, Buckley B, Cochran C, Dorey G, Grant A, Hagen S, Kilonzo M, McDonald A, McPherson G, Moore K, N'Dow J, Norrie J, Ramsay C, Vale L. Conservative treatment for urinary incontinence in Men After Prostate Surgery (MAPS): two parallel randomised controlled trials. Health Technol Assess. 2011 Jun;15(24):1290, iii-iv.

9) Hanchanale VS, McCabe JE, Javlé P. Radical prostatectomy practice in England. Urol J. 2010 Fall;7(4):243-8.

10) Alibhai SM, Leach M, Tomlinson G, et al. 30-day mortality and major complications after radical prostatectomy: influence of age and comorbidity. J Natl Cancer Inst 2005; 97:1525.

11) Eggener SE, Scardino PT, Walsh PC, et al. Predicting 15year prostate cancer specific mortality after radical prostatectomy. J Urol 2011; 185:869.

12) Defade BP, Carson CC 3rd, Kennelly MJ Postprostatectomy erectile dysfunction: the role of penile rehabilitation. Rev Urol. 2011;13(1):6-13. 